Case Report

\title{
Severe Short Stature in an Adolescent Male with Prader-Willi Syndrome and Congenital Adrenal Hyperplasia: A Therapeutic Conundrum
}

\author{
Meredith Wasserman, ${ }^{1}$ Erin M. Mulvihill, ${ }^{2}$ Angela Ganan-Soto, ${ }^{3}$ \\ Serife Uysal, ${ }^{4}$ and Jose Bernardo Quintos ${ }^{4}$ \\ ${ }^{1}$ The Warren Alpert Medical School, Brown University, Providence, RI, USA \\ ${ }^{2}$ College of Human Ecology, Cornell University, Ithaca, NY, USA \\ ${ }^{3}$ Alexian Brothers Women and Children's Hospital and Amita Health Medical Group, Hoffman Estates, IL, USA \\ ${ }^{4}$ Division of Pediatric Endocrinology, Rhode Island Hospital and Hasbro Children's Hospital, The Warren Alpert Medical School, \\ Brown University, Providence, RI, USA
}

Correspondence should be addressed to Jose Bernardo Quintos; jbquintos@brown.edu

Received 4 April 2017; Accepted 10 May 2017; Published 30 May 2017

Academic Editor: Wayne V. Moore

Copyright (C) 2017 Meredith Wasserman et al. This is an open access article distributed under the Creative Commons Attribution License, which permits unrestricted use, distribution, and reproduction in any medium, provided the original work is properly cited.

Congenital adrenal hyperplasia $(\mathrm{CAH})$ due to 21-hydroxylase deficiency results in excess androgen production which can lead to early epiphyseal fusion and short stature. Prader-Willi syndrome (PWS) is a genetic disorder resulting from a defect on chromosome 15 due to paternal deletion, maternal uniparental disomy, or imprinting defect. Ninety percent of patients with PWS have short stature. In this article we report a patient with simple-virilizing CAH and PWS who was overtreated with glucocorticoids for CAH and not supplemented with growth hormone for PWS, resulting in a significantly short adult height.

\section{Introduction}

Congenital adrenal hyperplasia (CAH) is a family of autosomal recessive disorders characterized by the inability to synthesize cortisol from cholesterol in the adrenal cortex. 21hydroxylase deficiency is the most common cause of CAH and results in excess androgen production due to shunting of intermediates in the steroidogenic pathway toward androgen synthesis. Excess androgen production causes the early fusion of epiphyseal plates, which stunts growth. Treatment for patients with CAH involves the delicate balance of suppressing adrenal androgens while maintaining normal growth.

Short adult stature is common in 21-hydroxylase deficiency. Final adult height in patients with $\mathrm{CAH}$ is $1.38 \mathrm{SD}$ lower than the population norm and their corrected height (final height minus genetic height potential) is $1.03 \mathrm{SD}$ lower than their genetic height potential [1]. This short stature is seen in CAH patients even in the presence of early glucocorticoid treatment to suppress excess androgen production.
Excess glucocorticoids can inhibit the pituitary production of growth hormone and contribute to short stature [2]. Growth hormone therapy was found to improve final height in patients with CAH by $9.2 \mathrm{~cm} \pm 6.7 \mathrm{~cm}$ in males and $10.5 \pm$ $3.7 \mathrm{~cm}$ in females [3]. It was also found that treatment with growth hormone can counter the growth-suppressing effects of glucocorticoids [4].

Prader-Willi syndrome (PWS) is a genetic disorder resulting from a defect within the Prader-Willi critical region on chromosome 15 due to paternal deletion, maternal uniparental disomy, or imprinting defect. PWS is characterized by short adult stature, morbid obesity, hypogonadism, and characteristic facial features such as narrow bifrontal diameter, almond-shaped eyes, and small mouth with downturned corners and thin upper lip [5]. Decreased growth hormone levels and serum levels of insulin-like growth factor 1 (IGF-1) and insulin-like growth factor binding protein 3 (IGFBPG-3) are found in $40-100 \%$ of children with PWS $[6,7]$. Additionally, $90 \%$ of patients with PWS have short 
stature [7]. In the absence of growth hormone treatment and subsequent pubertal growth spurt, average adult height in male and female patients with PWS is $155 \mathrm{~cm}$ and $148 \mathrm{~cm}$, respectively [7]. Patients treated with growth hormone were found to attain a mean adult height SDS of $-0.3 \pm 1.2$ [8]. In addition, growth hormone treatment has been shown to improve body composition by lowering body fat percentage and increasing lean body mass [9].

To our knowledge, no case of simultaneous PWS and $\mathrm{CAH}$ has been reported. Here, we report a patient with PWS and CAH who was overtreated with glucocorticoids for $\mathrm{CAH}$ and not supplemented with growth hormone for PWS, resulting in a significantly short adult height.

\section{Case Report}

We report the case of a 20-year-old Puerto Rican male with PWS and $\mathrm{CAH}$ who we initially evaluated when he was 17-year-old. He was born full term with birth weight 5 pounds, birth length 21 inches, and physical exam showing bilateral cryptorchidism and hypotonia. Karyotype is 46XY. He experienced feeding difficulties in the first year of life and had delayed milestones. At 3 years of age, he developed pubic hair and his laboratory examination showed 17-hydroxyprogesterone level $8,676 \mathrm{ng} / \mathrm{dL}$ and DHEAS $29 \mathrm{ug} / \mathrm{dL}$. He was diagnosed with $\mathrm{CAH}$ and prescribed hydrocortisone. He was treated with fludrocortisone for the first 1-2 years after diagnosis. At 9 years of age his dose of hydrocortisone was increased, most likely due to poor compliance to treatment and poor adrenal control. Over the years he struggled with obesity and learning and behavioral problems, including hyperactivity and short attention span. He was diagnosed with PWS at 12 years of age, showing a submicroscopic deletion of chromosome 15 (q11.2q11.2). He was not treated with growth hormone. He also had a bone age of left hand in an outside hospital when he was 12 years old and his bone age was reported as 16 years old.

He came to our clinic for the first time at age 17 years. He was taking hydrocortisone $40 \mathrm{mg}$ in the morning and $20 \mathrm{mg}$ in the evening (equivalent of $37.5 \mathrm{mg} / \mathrm{m}^{2} /$ day). Usual dose of hydrocortisone is $10-20 \mathrm{mg} / \mathrm{m}^{2} /$ day. Physical exam showed a short male with almond-shaped eyes, fair skin, narrow bifrontal diameter, upslanted palpebral fissures (Figure 1), and small hands (Figure 2). His height was $138.6 \mathrm{~cm} \quad(<5$ percentile; -5.3 height SDS), height age 10 years, weight $72.3 \mathrm{~kg}$ (72nd percentile; 0.6 SDS), BMI $37.48 \mathrm{~kg} / \mathrm{m}^{2}$ (>99th percentile), and blood pressure 124/56 mmHg. He was Tanner 3 for pubic hair and genitalia and testicular volume was 5$6 \mathrm{cc}$. His mother measured $159.8 \mathrm{~cm}$ and his father's reported height is $167.6 \mathrm{~cm}$. Based on parental heights his midparental target height is $170.2 \mathrm{~cm}$.

Laboratory investigation showed 17-hydroxyprogesterone $16 \mathrm{ng} / \mathrm{dL}$, testosterone $5 \mathrm{ng} / \mathrm{dL}$ (normal for 17-year-old male is $348-1197 \mathrm{ng} / \mathrm{dL}$ ), and renin $10.47 \mathrm{ng} / \mathrm{mL} / \mathrm{hr}$. Adrenal hormone assays were done by liquid chromatography tandem mass spectrometry at Esoterix Laboratory Services in Calabasas Hills, California, United States. Bone age of left hand was 17 years of age, consistent with his chronological age.

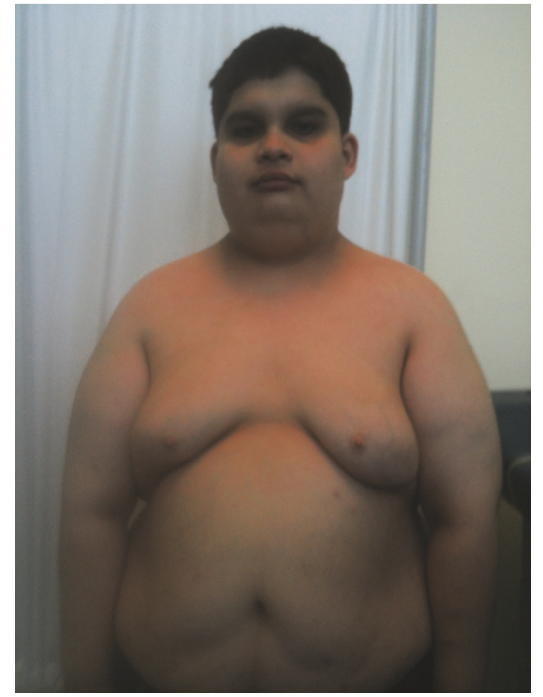

FIgure 1: Characteristic facial features of Prader-Willi syndrome.

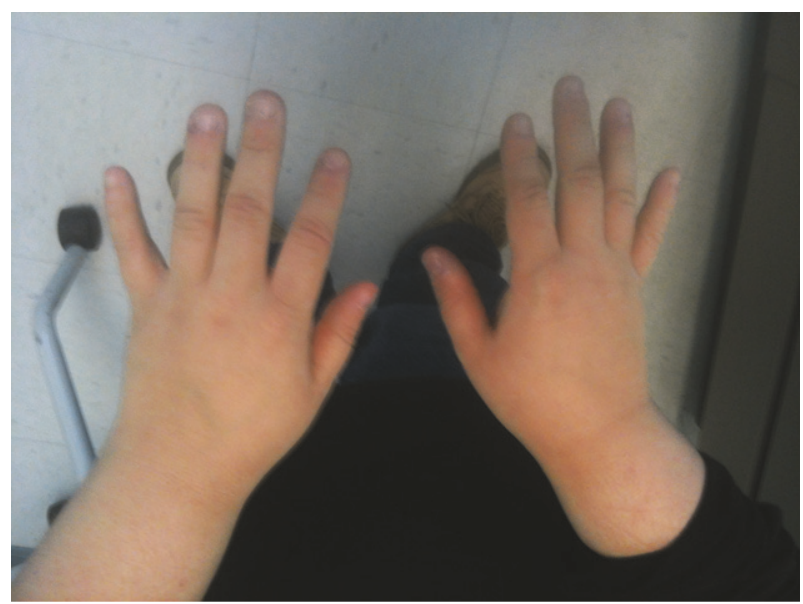

Figure 2: Small hands characteristic of Prader-Willi syndrome.

We decreased his hydrocortisone dosage to $20 \mathrm{mg}$ twice a day (equivalent $25 \mathrm{mg} / \mathrm{m}^{2} /$ day) with the goal of $17-$ hydroxyprogesterone level between 100 and $1000 \mathrm{ng} / \mathrm{dL}$ and androstenedione level normal for age and sex. His electrolytes were $\mathrm{Na}^{+} 135 \mathrm{mEq} / \mathrm{L}, \mathrm{Cl}^{-} 100 \mathrm{mEq} / \mathrm{L}, \mathrm{CO}_{2} 27 \mathrm{mEq} / \mathrm{L}$, and $\mathrm{K}^{+}$ $4.3 \mathrm{mEq} / \mathrm{L}$. Hologic DEXA scan showed bone mass density below expected range for age. Femoral neck $Z$-score was -3.2, total hip $Z$-score was -3.3 , and total body $Z$-score was -1.7 ( -1.0 to -2.5 SDS).

He returned to our clinic six months later and his laboratory work-up showed 17-hydroxyprogesterone $23 \mathrm{ng} / \mathrm{dL}$, androstenedione $<10 \mathrm{ng} / \mathrm{dL}$ (normal 17-72 ng/dL for Tanner 3), renin $3.43 \mathrm{ng} / \mathrm{mL} / \mathrm{hr}$, IGFBP-3 $2.8 \mathrm{mg} / \mathrm{L}$ (normal 2.5-4.8 mg/L), and IGF-1 $252 \mathrm{ng} / \mathrm{mL}$ (normal $161-467 \mathrm{mg} / \mathrm{mL}$, mean $290 \mathrm{mg} / \mathrm{mL}$ ). We further decreased hydrocortisone dose to $20 \mathrm{mg}$ in the morning and $10 \mathrm{mg}$ in the evening (equivalent $18 \mathrm{mg} / \mathrm{m}^{2} /$ day), which resulted in normal adrenal control (17-hydroxyprogesterone $426 \mathrm{ng} / \mathrm{dL}$ ). 
TABLE 1: Results of high dose ACTH stimulation test with 250 mcg cosyntropin.

\begin{tabular}{lccccc}
\hline Time (mins) & Cortisol $(\mathrm{ug} / \mathrm{dl})$ & 17-Hydroxyprogesterone $(\mathrm{ng} / \mathrm{dl})$ & Androstenedione $(\mathrm{ng} / \mathrm{dl})$ & Testosterone $(\mathrm{ng} / \mathrm{dl})$ & DHEA $(\mathrm{ng} / \mathrm{dl})$ \\
\hline 0 & 2.9 & 9,410 & 106 & 31 & $<20$ \\
60 & 2.7 & 11,000 & 77 & 44 & $<20$ \\
\hline
\end{tabular}

Pituitary gonadal axis evaluation showed $\mathrm{LH} 9.6 \mathrm{mIU} / \mathrm{mL}$, FSH $21 \mathrm{mIU} / \mathrm{mL}$, testosterone $139 \mathrm{ng} / \mathrm{dL}$, and androstenedione $35 \mathrm{ng} / \mathrm{dL}$, suggesting primary gonadal dysgenesis. Patient has not had testicular ultrasound to evaluate for testicular adrenal rest tumor (TART). An ACTH stimulation test to confirm the $\mathrm{CAH}$ diagnosis was done after stopping hydrocortisone for 24 hours. Results were consistent with simple-virilizing $\mathrm{CAH}$ due to 21-hydroxylase deficiency (Table 1). Genetic testing for mutations in the 21-hydroxylase gene has not been obtained. Testosterone cypionate $50 \mathrm{mg}$ IM every four weeks was started. This resulted in more aggressive behavior and violent outbursts prompting discontinuation of testosterone treatment.

\section{Discussion}

We report the case of a 20 -year-old male with simplevirilizing $\mathrm{CAH}$ and PWS, who probably had both periods of undertreatment and overtreatment of glucocorticoids and lack of growth hormone treatment for PWS, resulting in a significantly short adult height. He also displayed aggressive behavior after being treated with testosterone for hypogonadism associated with PWS. To the best of our knowledge, there has been no other reported case of a patient with both PWS and CAH.

The chance of one patient having both CAH and PWS is extremely rare. The worldwide incidence of severe classic CAH is 1 in 15,000 [10] and the incidence of PWS is estimated to be between 1 in 10,000 and 1 in 30,000 [11].

The late diagnosis of PWS and missed opportunity for growth hormone therapy contributed to his significantly short adult stature. His height is $138.6 \mathrm{~cm}$, or -5.3 height SDS. The average adult height of a male with untreated PWS is $155 \mathrm{~cm}$ (-3 height SDS) [7]. In one study, PWS patients treated with growth hormone achieved a mean adult height of -0.3 \pm 1.2 SDS, while untreated patients achieved a mean adult height of $-3.1 \pm 1$ SDS [8]. A retrospective study evaluating the effects of hydrocortisone treatment in patients with classical CAH showed that higher doses of glucocorticoids in children with $\mathrm{CAH}$ may result in decreased linear growth [12]. Additionally, a study of children with classic CAH found that the average final height for males treated with an average daily hydrocortisone dose of $19.7 \pm 2.9 \mathrm{mg} / \mathrm{m}^{2} /$ day was 163.1 $\pm 6.6 \mathrm{~cm}[13]$.

We hypothesize that periods of undertreatment and overtreatment with hydrocortisone contributed to his severe short stature. Factors that cause short adult stature in patients with 21-hydroxylase deficiency are (1) elevated adrenal androgens, which cause advanced epiphyseal maturation and premature epiphyseal fusion, (2) early or precocious puberty, which also leads to premature epiphyseal fusion, and (3) overtreatment with glucocorticoids [14]. Our patient also experienced premature epiphyseal fusion, as his bone age was 16 years at a chronological age 12. This premature epiphyseal fusion could be a result of periods of glucocorticoid undertreatment for CAH. Additionally, overtreatment with glucocorticoids most likely led to growth hormone suppression leading to poor growth velocity. This case reinforces the importance of growth hormone treatment for PWS and reduced glucocorticoid treatment for $\mathrm{CAH}$, especially when both disorders coexist in one patient. Additionally, our patient was born small for gestational age with a birth weight of 5 pounds. It was unclear if he had catch-up growth due to lack of growth charts from the early childhood period. This may also have contributed to his short stature.

Our patient's elevated FSH and LH levels and low testosterone levels indicate that he has primary hypogonadism. Eiholzer et al. found that boys with PWS have a combination of central and primary hypogonadism involving deficiency of $\mathrm{LH}$ and testosterone secretion at puberty and damage of the seminiferous tubules and Sertoli cells, resulting in reduced inhibin B levels and elevated FSH levels [15]. Additionally primary hypogonadism may be due to TART. Vanzulli et al. reported a prevalence of $27 \%$ of TART in a group of $30 \mathrm{CAH}$ patients with age range 9 to 32 years [16]. It is more commonly seen in patients with salt-wasting CAH; however TART also occurs in patients with simple-virilizing and nonclassical $\mathrm{CAH}$.

He displayed aggressive and violent behavior after testosterone replacement therapy, prompting discontinuation of therapy. It has been suggested that, to avoid aggressive behavior, testosterone should be administered daily as gels or patches instead of monthly depot intramuscular (IM) injections $[17,18]$. Depot testosterone preparations cause unpredictable peaks and troughs, which may cause mood instability. Others suggest reducing the testosterone dose for patients with PWS to one-third to one-half of the normally recommended dose [6].

This unique case highlights the importance of careful follow-up and monitoring of adrenal androgens in a patient with CAH. Glucocorticoid dosage should be adjusted to prevent premature epiphyseal fusion and to maximize growth. This case also highlights the importance of early diagnosis of PWS and initiation of growth hormone treatment. When hypotonia, feeding difficulties followed by obesity, characteristic facial features, and characteristics of hypogonadism present in an infant, PWS should be suspected [5]. This case also exemplifies the need for further research on appropriate testosterone therapy for males with PWS.

\section{Conflicts of Interest}

None of the authors have potential, perceived, or real conflicts of interest to disclose. 


\section{Authors' Contributions}

Meredith Wasserman, M.S., wrote first draft of manuscript and edited. Erin M. Mulvihill edited and revised manuscript drafts. Angela Ganan-Soto, M.D., performed data collection and edited manuscript, with direct care of patient. Serife Uysal, M.D., edited and revised manuscript drafts. Jose Bernardo Quintos, M.D., conceptualized manuscript, edited, and revised, with direct care of patient.

\section{References}

[1] K. Muthusamy, M. B. Elamin, G. Smushkin et al., "Adult height in patients with congenital adrenal hyperplasia: a systematic review and metaanalysis," Journal of Clinical Endocrinology and Metabolism, vol. 95, no. 9, pp. 4161-4172, 2010.

[2] A. Grigorescu-Sido, M. Bettendorf, E. Schulze, I. Duncea, and U. Heinrich, "Growth analysis in patients with 21-hydroxylase deficiency influence of glucocorticoid dosage, age at diagnosis, phenotype and genotype on growth and height outcome," Hormone Research, vol. 60, no. 2, pp. 84-90, 2003.

[3] K. Lin-Su, M. D. Harbison, O. Lekarev, M. G. Vogiatzi, and M. I. New, "Final adult height in children with congenital adrenal hyperplasia treated with growth hormone," Journal of Clinical Endocrinology and Metabolism, vol. 96, no. 6, pp. 1710-1717, 2011.

[4] D. B. Allen, J. R. Julius, T. J. Breen, and K. M. Attie, "Treatment of glucocorticoid-induced growth suppression with growth hormone," Journal of Clinical Endocrinology and Metabolism, vol. 83, no. 8, pp. 2824-2829, 1998.

[5] V. A. Holm, S. B. Cassidy, M. G. Butler et al., "Prader-Willi syndrome: consensus diagnostic criteria," Pediatrics, vol. 91, no. 2, pp. 398-402, 1993.

[6] M. Cataletto, M. Angulo, G. Hertz, and B. Whitman, "PraderWilli syndrome: a primer for clinicians," International Journal of Pediatric Endocrinology, vol. 2011, no. 1, 12 pages, 2011.

[7] P. Burman, E. M. Ritzén, and A. C. Lindgren, "Endocrine dysfunction in Prader-Willi syndrome: a review with special reference to GH," Endocrine Reviews, vol. 22, no. 6, pp. 787-799, 2001.

[8] M. A. Angulo, M. Castro-Magana, M. Lamerson, R. Arguello, S. Accacha, and A. Khan, "Final adult height in children with Prader-Willi syndrome with and without human growth hormone treatment," American Journal of Medical Genetics, Part A, vol. 143, no. 13, pp. 1456-1461, 2007.

[9] A. L. Carrel, S. E. Myers, B. Y. Whitman, J. Eickhoff, and D. B. Allen, "Long-term growth hormone therapy changes the natural history of body composition and motor function in children with prader-willi syndrome," Journal of Clinical Endocrinology and Metabolism, vol. 95, no. 3, pp. 1131-1136, 2010.

[10] D. P. Merke and S. R. Bornstein, "Congenital adrenal hyperplasia," The Lancet, vol. 365, no. 9477, pp. 2125-2136, 2005.

[11] B. J. Hurren and N. A. M. S. Flack, "Prader-Willi Syndrome: a spectrum of anatomical and clinical features," Clinical Anatomy, vol. 29, no. 5, pp. 590-605, 2016.

[12] W. Bonfig, S. B. Pozza, H. Schmidt, P. Pagel, D. Knorr, and H. P. Schwarz, "Hydrocortisone dosing during puberty in patients with classical congenital adrenal hyperplasia: An evidencebased recommendation," Journal of Clinical Endocrinology and Metabolism, vol. 94, no. 10, pp. 3882-3888, 2009.

[13] Z. Aycan, S. Akbuga, E. Cetinkaya, G. Ocal, and M. Berberoglu, "Final height of patients with classical congenital adrenal hyperplasia," The Turkish Journal of Pediatrics, vol. 51, no. 6, pp. 539-544, 2009.

[14] J. B. Q. Quintos, M. G. Vogiatzi, M. D. Harbison, and M. I. New, "Growth hormone therapy alone or in combination with gonadotropin-releasing hormone analog therapy to improve the height deficit in children with congenital adrenal hyperplasia," Journal of Clinical Endocrinology and Metabolism, vol. 86, no. 4, pp. 1511-1517, 2001.

[15] U. Eiholzer, D. l'Allemand, V. Rousson et al., "Hypothalamic and gonadal components of hypogonadism in boys with PraderLabhart-Willi syndrome," Journal of Clinical Endocrinology and Metabolism, vol. 91, no. 3, pp. 892-898, 2006.

[16] A. Vanzulli, A. DelMaschio, and P. Paesano, "Testicular masses in association with adrenogenital syndrome: US findings," Radiology, vol. 183, no. 2, pp. 425-429, 1992.

[17] S. B. Cassidy and D. J. Driscoll, "Prader-Willi syndrome," European Journal of Human Genetics, vol. 17, no. 1, pp. 3-13, 2009.

[18] F. Benarroch, H. J. Hirsch, L. Genstil, Y. E. Landau, and V. Gross-Tsur, "Prader-Willi Syndrome: Medical Prevention and Behavioral Challenges," Child and Adolescent Psychiatric Clinics of North America, vol. 16, no. 3, pp. 695-708, 2007. 


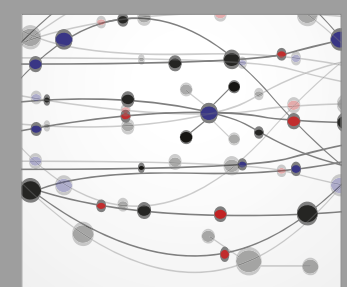

The Scientific World Journal


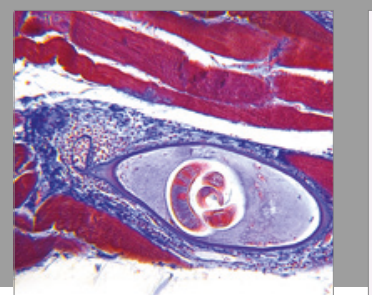

Gastroenterology Research and Practice
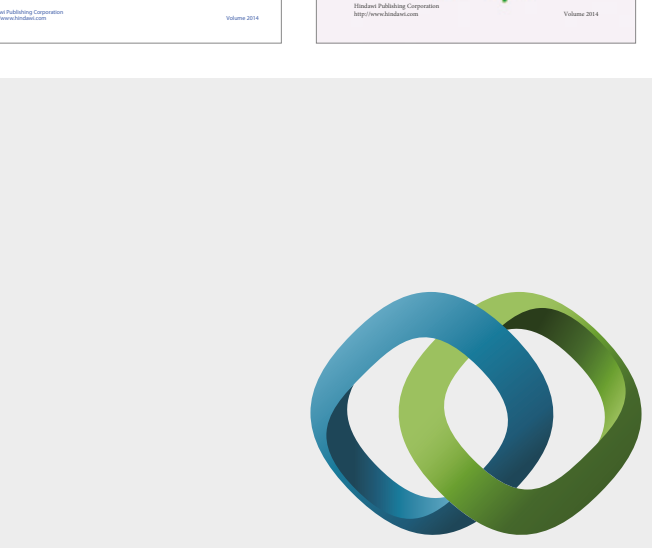

\section{Hindawi}

Submit your manuscripts at

https://www.hindawi.com
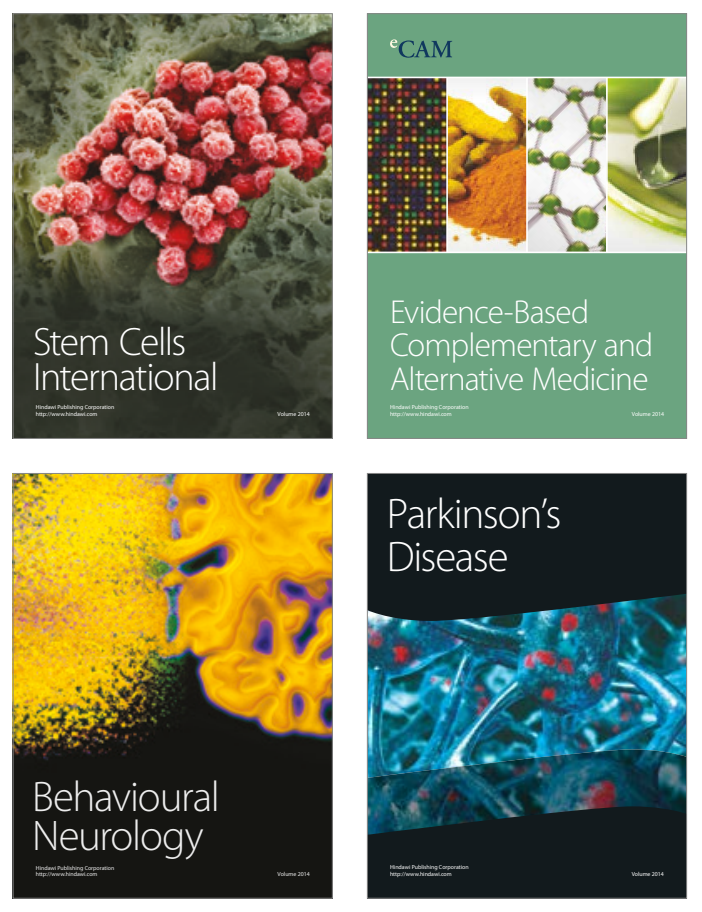
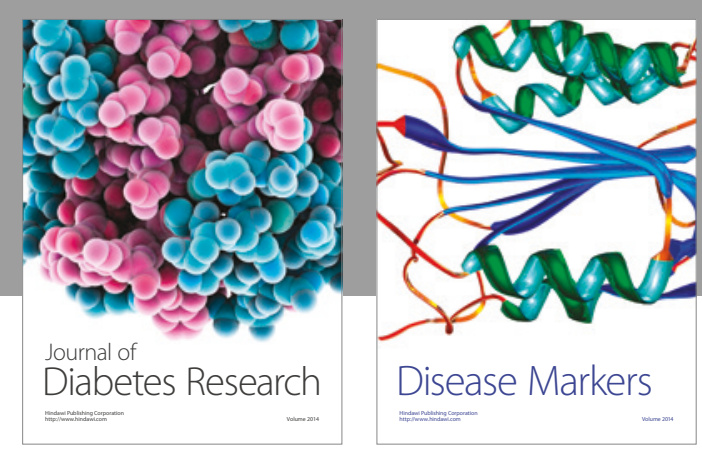

Disease Markers
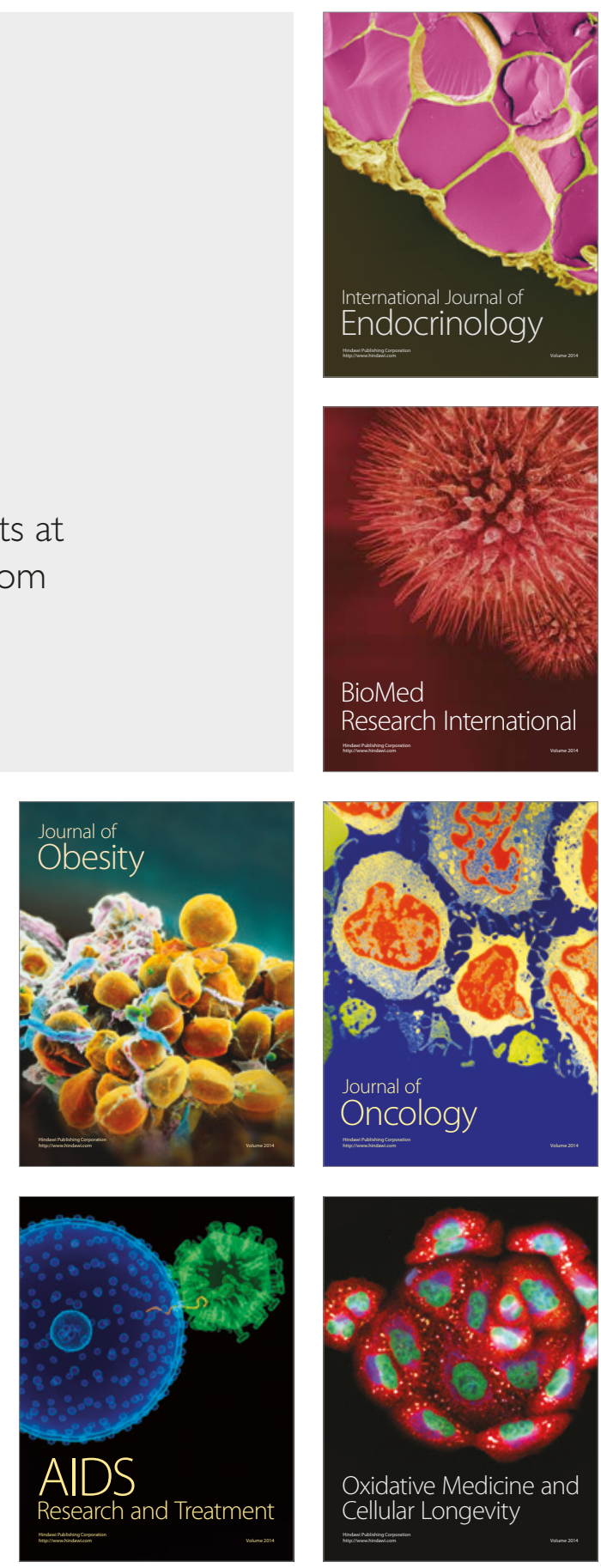